University of Windsor

Scholarship at UWindsor

Mechanical, Automotive \& Materials

Department of Mechanical, Automotive \& Engineering Publications

Materials Engineering

$12-2010$

\title{
Coordinating production and recycling decisions with stochastic demand and return
}

Jianmai Shi

Guoqing Zhang

University of Windsor

Jichang Sha

Saman Hassanzadeh Amin

University of Windsor

Follow this and additional works at: https://scholar.uwindsor.ca/mechanicalengpub

Part of the Business Administration, Management, and Operations Commons, Environmental Engineering Commons, Industrial Engineering Commons, and the Operations and Supply Chain Management Commons

\section{Recommended Citation}

Shi, Jianmai; Zhang, Guoqing; Sha, Jichang; and Amin, Saman Hassanzadeh. (2010). Coordinating production and recycling decisions with stochastic demand and return. Journal of Systems Science and Systems Engineering, 19 (4), 385-407.

https://scholar.uwindsor.ca/mechanicalengpub/14

This Article is brought to you for free and open access by the Department of Mechanical, Automotive \& Materials Engineering at Scholarship at UWindsor. It has been accepted for inclusion in Mechanical, Automotive \& Materials Engineering Publications by an authorized administrator of Scholarship at UWindsor. For more information, please contact scholarship@uwindsor.ca. 


\title{
Coordinating production and recycling decisions with stochastic demand and return
}

\author{
Jianmai Shi ${ }^{\mathrm{a}, \mathrm{b}}$, Guoqing Zhang ${ }^{\mathrm{b}^{*}}$, Jichang Sha ${ }^{\mathrm{a}}$, Saman Hassanzadeh Amin ${ }^{\mathrm{b}}$ \\ ${ }^{a}$ School of Information System and Management, National University of Defense Technology, Changsha, Hunan, \\ China \\ ${ }^{\mathrm{b}}$ Department of Industrial and Manufacturing Systems Engineering, University of Windsor, Windsor, Ontario, \\ Canada
}

*Corresponding author. Email: gzhang@uwindsor.ca

\begin{abstract}
In this paper, the joint production and recycling problem is investigated for a hybrid manufacturing and remanufacturing system where brand-new products are produced in the manufacturing plant and recycled products are remanufactured into as-new products in the remanufacturing facility. Both the brand-new products and remanufactured products are used to satisfy customer demands. Returns of used products that are recycled from customers are assumed to be stochastic and nonlinearly price-dependent. A mathematical model is proposed to maximize the overall profit of the system through simultaneously optimizing the production and recycling decisions, subject to two capacity constraints - the manufacturing capacity and the remanufacturing capacity. Based on Lagrangian relaxation method, subgradient algorithm and heuristic algorithm, a solution approach is developed to solve the problem. A representative example is presented to illustrate the system, and managerial analysis indicates that the uncertainties in demand and return have much influence on the production and recycling policy. In addition, twenty randomly produced examples are solved, and computational results show that the solution approach can obtain very good solutions for all examples in reasonable time.
\end{abstract}

Keywords: closed loop supply chain; uncertain demand; uncertain return; reverse logistics; Lagrangian relaxation

\section{Introduction}

Due to increased concerns on environment, awareness of natural resource limitation and government legislations, closed loop supply chain (CLSC) has received considerable attention throughout last decades. In US and EU, many recent producer responsibility laws require manufacturers to take the responsibility of their products after use, and encourage them to collect and reuse their products (Guide et al., 2001; Mitra, 2007). In U.S. more than 73,000 firms participate in remanufacturing and act some role in CLSC, while about $\$ 53$ billion remanufactured products are sold annually and over 350,000 work opportunities are created (Lund, 1998; Nasr et al., 1998).

Another important driver for CLSC is its economic potential. Environmental friendly products have more attractiveness to customers, and their market increases quickly, which has been over $\$ 200$ billions (Carter and Ellram 1998). Meanwhile, manufacturers can reduce their production cost through reusing the components and materials in used products. Compared with normal production, manufacturers can save about 40-60 percent of the cost while paying for only 20 percent of the manufacturing effort (Dowlatshahi 2000). As a result, CLSC has become one of the most sustainable strategies for the 21 th century.

In this paper, a hybrid manufacturing and remanufacturing system is investigated, where the manufacturer has two alternatives to satisfy customer demands: either manufacturing brand-new products or remanufacturing returns into as-new products. In the remanufacturing process, the manufacturer recycles used products from customers and remanufactures them into as-new products. Usually, remanufactured products are not enough to satisfy all the demands, thus brand-new products are produced in the manufacturing plant. In order to obtain the 
overall profit of the hybrid system, the manufacturer has to jointly optimize two kinds of decisions: determining the production quantities for brand-new products and remanufactured products to satisfy the demand, and determining the recycling price to buy back enough used products for remanufacturing.

To address the joint production and recycling problem, a mathematical model is developed for the hybrid system to maximize the manufacturer's total expected profit, subject to the manufacturing and remanufacturing capacities. The main contributions of this paper are as follows. First, the return quantity of used products is assumed to be nonlinearly price-dependent, and a new model is presented to characterize the relationship between the recycling price and the return quantity. Second, two capacities are considered in the problem, which are the capacity for the manufacturing plant and the capacity for the remanufacturing facility. Third, through combining subgradient algorithm and heuristic algorithm, a Lagrangian based solution approach is developed to solve the problem. Additionally, the uncertainties of demand and return are considered, and their influence on the hybrid system is analyzed.

The organization of the paper is as follows. Related literature review is presented in Section 2. Section 3 provides a detailed description for the system and develops the mathematical model. Section 4 presents a solution approach based Lagrangian relaxation, followed by computational results and managerial analysis in Section 5. Finally, conclusions are presented in Section 6.

\section{Literature review}

Many aspects of CLSC have been investigated, such as return flow management, distribution planning, production management, inventory control and remanufactured product pricing (Fleischmann et al., 1997; Pokharel and Mutha, 2009). During 1995-2005, more than 180 articles are published on main international journals in production and operations research area (Rubio et al., 2008). Over the past decades, closed loop supply chain has grown up from solving isolated OR subproblems and become a critical research area in operations research and management (Guide and Van Wassenhove, 2009).

Production planning is a challenging topic in CLSC, especially when both manufacturing and remanufacturing processes are involved. Compared to the traditional system, the production planning and control of the hybrid manufacturing and remanufacturing system is more complex. The correlation between demand and return uncertainties is the source of these complexities and has much influence on the PUSH and PULL controlled production/inventory policies in the hybrid system (Van Der Laan et al., 1999). Balancing return with demand has been considered to be one of the most important challenges to the production planning and control for remanufacturing (Guide, 2000).

Various models have been presented to optimize the production planning problem for different closed loop supply chains. Inderfurth et al. (2001) develop a period review model to solve the production planning problem for an uncertain remanufacturing system where there are multiple reuse options for the used products. Through extending a traditional Poisson-demand inventory model, Fleischmann et al. (2002) present a new inventory model for a hybrid system where used products are taken back and enter the production process again.

Ferrer and Swaminathan (2006) investigate a reverse system where the firm produces new goods with monopoly in the first period and offers new products as well as remanufactured products in subsequent periods. The monopoly and duopoly situations are both analyzed. The results show that, when competition increases, the original equipment manufacturer (OEM) prefers to completely remanufacture all available used product returns and resell them at a lower price.

Dobos and Richter (2004) study a production/recycling system where the production-inventory policy is predetermined and the demand is assumed to be constant. Zhou et al. (2006) investigate a hybrid system with manufacturing and remanufacturing, in which the inventory control strategy is an automatic pipeline, inventory 
and order based production control system. Choi et al. (2007) develop a joint EOQ and EPQ model for an inventory system where the stationary demand can be satisfied by newly purchased products and remanufactured products. Rubio and Corominas (2008) present a production management model and investigate under what conditions a reverse logistics system can be implemented in a lean production environment. They analyze the transfer of capacity between manufacturing and remanufacturing and present the optimal production policies.

The used product returns are usually uncertain and have a direct influence on the production/inventory management. Guide and Van Wassenhove (2001) analyze the potential economic attractiveness of remanufacturing and show that used product acquisition management may serve as a foundation tool to control the operational planning and management activities in closed loop supply chain. They encourage firms to positively acquire used products according to their quality. Guide et al. (2003) further investigate a closed loop supply chain where the quantity, quality and timing of returns can be controlled by the price offered to buy back the used products. Fleischmann and Kuik (2003) examine the impact of product return flow on inventory management.

Inderfurth (2005) investigate the influence of uncertainties on recovery behavior in a closed loop system. By a numerical analysis, it is shown that the product recovery management becomes much difficult because the manufacturer usually has to balance the production, recovery and disposal decisions under considerable uncertainties of demand and return. Dobos and Richter (2006) consider the quality of the used product in an integrated production-recycling system, and show that it is better for the manufacturer to buy back only the reusable products. In a closed loop supply chain studied by Jayaraman (2006), the used products are acquired by a certain price according to their quality.

$\mathrm{Qu}$ and Williams (2008) investigate an automotive reverse system where the automotive shredder usually balances the quality and quantity of the incoming hulks by adjusting their acquisition prices. A nonlinear programming formulation is presented for the automotive reverse production planning and pricing problem, in which the quantity of the incoming hulks is a function of the hulk purchase price. Liang et al. (2009) present a model to evaluate the acquisition price of the used products. In the model the acquisition price is determined based on the manufacturing cost and the anticipated future sale prices of the remanufactured products.

So far, the uncertainties of the return flow have also been widely investigated, and used product pricing has been widely realized as a tool to decrease these uncertainties. But there still needs a further investigate on how to integrate this tool with production/inventory control policy of the closed loop supply chain. When the production and recycle activities are optimized coordinately, more value and profit of the hybrid manufacturing and remanufacturing system can be obtained.

\section{Model formulation}

\subsection{The framework and assumptions}

In the hybrid manufacturing and remanufacturing system, the manufacturer can produce multiple products through two channels: either producing brand-new products in the manufacturing plant or remanufacturing the recycled products and bringing them into 'as-new' conditions in the remanufacturing facility. The framework of the system is presented in Figure 1. In the remanufacturing process, the manufacturer first buys back the used products and stock them in a recoverable inventory where the used products are sent to the remanufacturing facility according to the remanufacturing order. When the used products are recycled, they are carefully inspected and only are the products that can be remanufactured bought back. Then in the remanufacturing facility, the recycled products are disassembled into parts which should enter a quality test. The parts satisfying 
the quality requirements are reused, while the parts with lower quality are repaired, upgraded or replaced. Finally, these parts are remanufactured into 'as-new' products. Most of the time, the units of remanufactured products are not enough to satisfy all the demands. Thus, brand-new products need to be produced at the manufacturing facility. There is no difference between brand-new products and remanufactured ones, and both of them are stocked in the serviceable inventory to satisfy the demands.

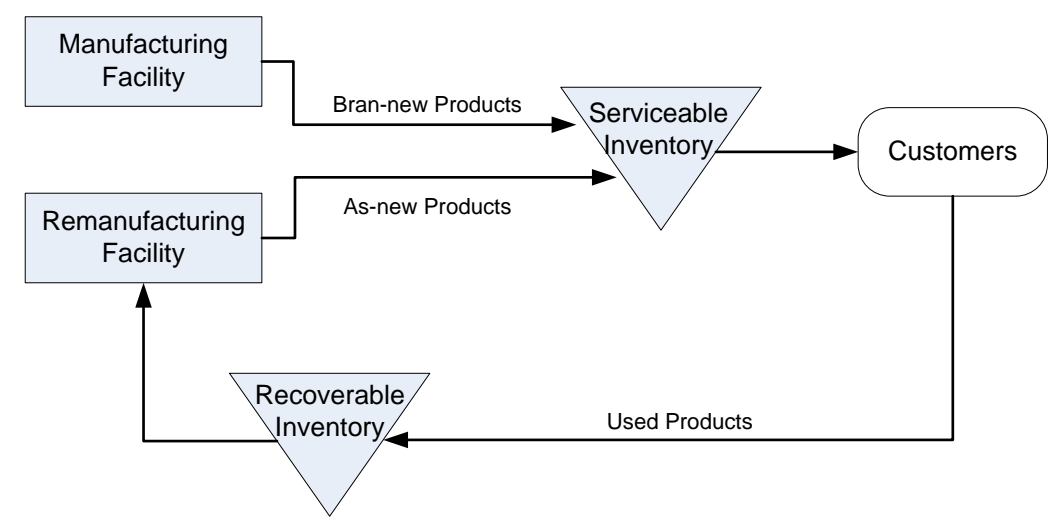

Figure 1 Framework for the hybrid manufacturing and remanufacturing system

The manufacturer's objective is to maximize the total expected profit for the whole system. To achieve the goal, the manufacturer should optimize the production and recycle decisions together. In the production decision, the manufacturing and remanufacturing quantities are determined. Therefore, the stocking level is determined for the serviceable inventory. In the recycling decision, the manufacturer should determine how much to pay for the used products to recycle enough used products for remanufacturing but not recycle too many products because of overstocking cost. The problem can be optimized by the mathematical model.

Before presenting the model, some assumptions are introduced.

- There is no distinction between a brand-new product and a remanufactured product, and they are sold together in the same market at the same price.

- Only the used products satisfying certain quality parameters are bought back and all of them can be remanufactured into as-new products.

- The demands for all products are uncertain and independent of each other.

- The return is price-sensitive and stochastic. The relationship between return and price is known, which is $\tilde{R}_{i}\left(\operatorname{Pr}_{i}, u_{i}\right)=R_{i}\left(\operatorname{Pr}_{i}\right)+u_{i}$, where $\operatorname{Pr}_{i}$ is the recycling price of used product $i$; $R\left(\operatorname{Pr}_{i}\right)=a_{i} e^{b_{i} \mathrm{Pr}_{i}}$ is the expected return quantity of used product $i\left(a_{i} \geq 0\right.$ and $\left.b_{i}>0\right)$ and $u_{i}$ is a random return defined on the range $\left[A_{i}, B_{i}\right]$ with mean $\mu_{i}^{r}$ and standard deviation $\sigma_{i}^{r}$.

- Only single period is considered, thus the return and the demand are assumed to be independent identically distributed.

In economics literatures, both additive and multiplicative (exponential) decreasing functions are widely used to represent the relationship between demand and the selling price (Petruzzi and Data 1999). It is natural to use similar increasing functions to capture the dependency between return quantity and recycling price, including the additive form, like $R(\operatorname{Pr})=a+b \operatorname{Pr}$, and the multiplicative forms, such as $R(\operatorname{Pr})=a e^{b \operatorname{Pr}}$, $R(\operatorname{Pr})=a \operatorname{Pr}^{b}$ and $R(\operatorname{Pr})=a \log _{b} \operatorname{Pr}$. The additive case has been studied in Bakal and Akcali (2006). In this paper, we investigate one of the multiplicative functions, $R(\operatorname{Pr})=a e^{b \operatorname{Pr}}$. Analogous results for this paper also apply for the other two multiplicative price-sensitive return functions. 


\subsection{Model formulation}

The following notations are used in the formulation of the joint production and recycling problem for the hybrid manufacturing and remanufacturing system:

Indices:

$i=1, \ldots, I:$ index of products

\section{Parameters:}

$p_{i}=$ the selling price of product $i$

$S_{i}=$ per unit overstocking cost of product $i$

$g_{i}=$ per unit understocking cost of product $i$

$c p_{i}=$ the unit production cost of brand-new product $i$

$c r_{i}=$ the unit remanufacturing cost of used product $i$, which is much less than $c p_{i}$

$h r_{i}=$ the unit inventory cost of used product $i$

$m s_{i}=$ the capacity consumed by producing one unit of product $i$

$r s_{i}=$ the capacity consumed by remanufacturing one unit of used product $i$

$M C=$ the total manufacturing capacity

$R C=$ the total remanufacturing capacity

$f_{i}^{d}(\cdot), F_{i}^{d}(\cdot)=$ pdf and cdf of the distribution of the demand Di for product $i$

$\mu_{i}^{d}=$ the mean of demand for product $i$

$\sigma_{i}^{d}=$ the standard deviation of demand for product $i$

$f_{i}^{r}(\cdot), F_{i}^{r}(\cdot)=$ pdf and cdf of the distribution of the random return $u_{i}$ for product $i$

$\mu_{i}^{r}=$ the mean of the random return $u_{i}$

$\sigma_{i}^{r}=$ the standard deviation of the random return $u_{i}$.

\section{Variables:}

$Q_{i}=$ the stocking quantity of product $i$

$X p_{i}=$ the newly manufacturing quantity of product $i$

$\operatorname{Pr}_{i}=$ the unit recycling price of the used product $i$

$X r_{i}=$ the remanufacturing quantity of product $i$

$z_{i}=X r_{i}-R\left(\operatorname{Pr}_{i}\right)$, where $R\left(\operatorname{Pr}_{i}\right)=a_{i} e^{b_{i} \mathrm{Pr}_{i}}$, then $X r_{i}=a_{i} e^{b_{i} \mathrm{Pr}_{i}}+z_{i}$.

The production cost, $c p_{i}$, is a sum of the costs related with manufacturing one unit of brand-new product $i$, which includes all the material and components cost, manufacturing and other related costs. The remanufacturing cost, $c r_{i}$, does not include the cost used to buy back the used products or the parts reused from the used products, but includes the cost for dismantling, inspection, quality assurance, remanufacturing, components used to replace the worn out ones and other remanufacturing related costs.

The model for the production and recycling problem can be formulated as follows:

$\operatorname{Max}$

$$
\begin{aligned}
R=\sum_{i=1}^{I} & \left\{\int_{0}^{Q_{i}}\left[p_{i} D_{i}-s_{i}\left(Q_{i}-D_{i}\right)\right] f_{i}^{d}\left(D_{i}\right) d D_{i}+\int_{Q_{i}}^{\infty}\left[p_{i} Q_{i}-g_{i}\left(D_{i}-Q_{i}\right)\right] f_{i}^{d}\left(D_{i}\right) d D_{i}\right\} \\
& -\sum_{i=1}^{I} c p_{i} X p_{i}-\sum_{i=1}^{I}\left(c r_{i}+\operatorname{Pr}_{i}\right) X r_{i}-\sum_{i=1}^{I} \int_{z_{i}}^{B_{i}}\left(h r_{i}+\operatorname{Pr}_{i}\right)\left(u_{i}-z_{i}\right) f_{i}^{r}\left(u_{i}\right) d u_{i}
\end{aligned}
$$


subject to

$$
\begin{aligned}
& \sum_{i=1}^{I} m s_{i} X p_{i} \leq M C, \\
& \sum_{i=1}^{I} r s_{i} X r_{i} \leq R C, \\
& X p_{i}+X r_{i}=Q_{i}, \quad \forall i, \\
& X r_{i}=a_{i} e^{b_{i} \operatorname{Pr}_{i}}+z_{i}, \quad \forall i, \\
& A_{i} \leq z_{i} \leq n_{i} \sigma_{i}^{r}, \quad \forall i, \\
& X p_{i} \geq 0, \quad \operatorname{Pr}_{i} \geq 0, \quad X r_{i} \geq 0, Q_{i} \geq 0, \forall i .
\end{aligned}
$$

In the objective function, the first term is the total expected revenue minus the overstocking cost and the understocking cost. The second term is the production cost of brand-new products. The third and fourth terms are the remanufacturing related costs which include the remanufacturing cost, the recycling and overstocking costs of the used products.

Similar to Inderfurth and Van Der Laan (2001) and Inderfurth et al. (2001), the understocking costs of used products are not considered in the objective function. But the understocking risk is considered by constraint (6). In constraints (6), the value of $z_{i}$ is restricted and $n_{i}$ is a parameter that can be adjusted according to the requirement of the manufacturer. $n_{i}$ can be set to negative or positive, and the understocking risk of used product $i$ can controlled in an acceptable level by adjusting the value of $n_{i}$. Since the understocking cost of the return is not included in the objective function, it is just an approximation of the total expected profit. The same approximating and handling strategy for the understocking risk of the return has been adopted in Rouf and Zhang (2009).

Constraint (2) is the crucial capacity restriction for manufacturing. Constraint (3) is the crucial capacity restriction for remanufacturing. Constraint (4) ensures that the stocking quantity is a sum of the manufacturing quantity and the remanufacturing quantity. Constraints (5) restrict the relationship between the remanufacturing quantity and the recycle price of used products. Constraints (6) restrict the value range of $z_{i}$. Constraints (7) are nonnegative constraints for the variables.

In formula (1)-(7), it can be seen that there is no constraint to restrict the upper bound of the recycling price. The recycling price can not increase infinitely because the objective function is to maximize the expected profit. There is an upper bound for the recycling price in the optimal solution, which is explained in detail in Section 4.1.1.

\section{Solution approach}

The proposed model is a nonlinear programming model, which can be solved by many methods, such as Lagrangian method, feasible direction methods, and interior point methods. . We develop a Lagrangian method to solve the problem based on the following reasons: first, the model has a separable structure that it can be decomposed into independent subproblems when constraints (2) and (3) are relaxed; second, the numbers of variables and constraints increase fast when the number of products increases, which means that the problem is difficult to solve when the number of products becomes very large. Lagrangian method based on the decomposition strategy has advantages to solve large scale problems.

There are three basic phases for the Lagrangian based solution approach: first, the Lagrangian dual problem is obtained by relaxing capacity constraints (2) and (3); then, the Lagrangian dual problem is solved by 
subgradient algorithm. The dual solution obtained by subgradient algorithm provides an upper bound to the original problem, but it may be not primal feasible, such as it may violate constraints (2) or (3). Therefore, in the last phase, a heuristic algorithm is developed to form a feasible solution from the dual bound.

\subsection{Lagrangian Relaxation}

Constraints (2) and (3) are relaxed and the Lagrangian dual problem can be described as follows:

$$
\begin{aligned}
\operatorname{Min}_{(\lambda, \eta)\left(Q_{i}, X p_{i}, X X_{i}, \mathrm{Pr}_{i}, z_{i}\right)} L R & =\sum_{i=1}^{I}\left\{\int_{0}^{Q_{i}}\left[p_{i} D_{i}-s_{i}\left(Q_{i}-D_{i}\right)\right] f_{i}^{d}\left(D_{i}\right) d D_{i}+\int_{Q_{i}}^{\infty}\left[p_{i} Q_{i}-g_{i}\left(D_{i}-Q_{i}\right)\right] f_{i}^{d}\left(D_{i}\right) d D_{i}\right\} \\
& -\sum_{i=1}^{I} c p_{i} X p_{i}-\sum_{i=1}^{I}\left(c r_{i}+\operatorname{Pr}_{i}\right) X r_{i}-\sum_{i=1}^{I} \int_{z_{i}}^{B_{i}}\left(h r_{i}+\operatorname{Pr}_{i}\right)\left(u_{i}-z_{i}\right) f_{i}^{r}\left(u_{i}\right) d u_{i} \\
& +\lambda\left(M C-\sum_{i=1}^{I} m s_{i} X p_{i}\right)+\eta\left(R C-\sum_{i=1}^{I} r s_{i} X r_{i}\right)
\end{aligned}
$$

subject to (4)-(7).

In the objective function (8), $\lambda$ and $\eta$ are the Lagrange multiplier associated with the relaxed constraints (2) and (3) respectively. For any fixed value of the Lagrange multipliers $\lambda$ and $\eta$, the relaxed problem can be decomposed into $I$ independent single product subproblems.

\section{Subproblem $L R P_{i}$ :}

$\operatorname{Max}$

$$
\begin{aligned}
L R P_{i}= & \int_{0}^{Q_{i}}\left[p_{i} D_{i}-s_{i}\left(Q_{i}-D_{i}\right)\right] f_{i}^{d}\left(D_{i}\right) d D_{i}+\int_{Q_{i}}^{\infty}\left[p_{i} Q_{i}-g_{i}\left(D_{i}-Q_{i}\right)\right] f_{i}^{d}\left(D_{i}\right) d D_{i} \\
& -\left(c p_{i}+\lambda m s_{i}\right) X p_{i}-\left(c r_{i}+\eta r s_{i}+\operatorname{Pr}_{i}\right) X r_{i}-\int_{z_{i}}^{B_{i}}\left(h r_{i}+\operatorname{Pr}_{i}\right)\left(u_{i}-z_{i}\right) f_{i}^{r}\left(u_{i}\right) d u_{i}
\end{aligned}
$$

subject to

$$
\begin{gathered}
X p_{i}+X r_{i}=Q_{i}, \\
X r_{i}=a_{i} e^{b_{i} \mathrm{Pr}_{i}}+z_{i}, \\
A_{i} \leq z_{i} \leq n_{i} \sigma_{i}^{r}, \\
X p_{i} \geq 0, \operatorname{Pr}_{i} \geq 0, X r_{i} \geq 0, Q_{i} \geq 0 .
\end{gathered}
$$

Substituting (9) into (8), the objective function of the relaxed problem can be described as follows:

$$
L R=\sum_{i=1}^{I} L R P_{i}+\lambda M C+\eta R C .
$$

\subsubsection{Properties of subproblem $L R P_{i}$}

For fixed values of the Lagrange multipliers $\lambda$ and $\eta$, the solution for the relaxed problem can be obtained by solving the subproblems $L R P_{i}$ for $i=1, \ldots, I$. Subproblem $L R P_{i}$ consists of five variables and four constraints. Although the variables and constraints can be reduced by substituting constraints (4) and (5) into the objective function, it is still difficult to obtain the optimal solution for the subproblem. Therefore, some properties of subproblem $L R P_{i}$ are investigated, through which the five-variable subproblem is reformulated into three single-variable subproblems that are easy to solve.

In subproblem $L R P_{i}$, if the remanufacturing quantity $X r_{i}$ is fixed, the decisions related with remanufacturing can be separated from the problem. Let $T R C_{i}$ denote the expected remanufacturing related cost, 
then:

$$
T R C_{i}=\left(c r_{i}+\eta r s_{i}+\operatorname{Pr}_{i}\right) X r_{i}+\int_{z_{i}}^{B_{i}}\left(h r_{i}+\operatorname{Pr}_{i}\right)\left(u_{i}-z_{i}\right) f_{i}^{r}\left(u_{i}\right) d u_{i}
$$

subject to

$$
\begin{aligned}
& X r_{i}=a_{i} e^{b_{i} \mathrm{Pr}_{i}}+z_{i}, \\
& A_{i} \leq z_{i} \leq n_{i} \sigma_{i}^{r}, \\
& \operatorname{Pr}_{i} \geq 0 .
\end{aligned}
$$

Proposition 1: For any fixed $X r_{i}$, there are unique $\operatorname{Pr}_{i}^{*}$ and $z_{i}^{*}$ to minimize $T R C_{i}$, which are presented below:

a) if $X r_{i} \geq a_{i}+n_{i} \sigma_{i}^{r}, \operatorname{Pr}_{i}^{*}=\frac{1}{b_{i}} \ln \left(\frac{X r_{i}-n_{i} \sigma_{i}^{r}}{a_{i}}\right)$ and $z_{i}^{*}=n_{i} \sigma_{i}^{r}$;

b) if $X r_{i} \leq a_{i}+n_{i} \sigma_{i}^{r}, \operatorname{Pr}_{i}^{*}=0$ and $z_{i}^{*}=X r_{i}-a_{i}$.

The proof of Proposition 1 is provided in the Appendix.

Proposition 1 shows that the optimal recycling price of the used product $i$ is determined uniquely as a function of $X r_{i}$.

Proposition 2: For a fixed $Q_{i}$, if $a_{i}-n_{i} \sigma_{i}^{r}-\Theta_{i}\left(n_{i} \sigma_{i}^{r}\right)>0$

and $-\frac{a_{i}+n_{i} \sigma_{i}^{r}+\Theta_{i}\left(n_{i} \sigma_{i}^{r}\right)}{a_{i} b_{i}}+\left(c p_{i}+\lambda m s_{i}\right)-\left(c r_{i}+\eta r s_{i}\right)>0$, the optimal solutions to maximize function $L R P_{i}$ are as follows:

a) if $Q_{i} \geq X r_{i}^{H}, \operatorname{Pr}_{i}^{*}=\frac{1}{b_{i}} \ln \left(\frac{X r_{i}^{H}-n_{i} \sigma_{i}^{r}}{a_{i}}\right), z_{i}^{*}=n_{i} \sigma_{i}^{r}, X r_{i}^{*}=X r_{i}^{H}$ and $X p_{i}^{*}=Q_{i}-X r_{i}^{H}$;

b) if $a_{i}+n_{i} \sigma_{i}^{r} \leq Q_{i} \leq X r_{i}^{H}, \operatorname{Pr}_{i}^{*}=\frac{1}{b_{i}} \ln \left(\frac{Q_{i}-n_{i} \sigma_{i}^{r}}{a_{i}}\right), z_{i}^{*}=n_{i} \sigma_{i}^{r}, X r_{i}^{*}=Q_{i}$ and $X p_{i}^{*}=0$;

c) if $Q_{i} \leq a_{i}+n_{i} \sigma_{i}^{r}, \operatorname{Pr}_{i}^{*}=0, z_{i}^{*}=Q_{i}-a_{i}, X r_{i}^{*}=Q_{i}$ and $X p_{i}^{*}=0$,

where $\Theta_{i}\left(n_{i} \sigma_{i}^{r}\right)=\int_{n_{i} \sigma_{i}^{r}}^{B_{i}}\left(u_{i}-n_{i} \sigma_{i}^{r}\right) f_{i}^{r}\left(u_{i}\right) d u_{i}$ and $X r_{i}^{H}$ is the unique solution that satisfies $d L R P 2_{i} / d X r_{i}=0$ (It is explained in the proof).

The proof of Proposition 2 is provided in the Appendix. The two conditions in Proposition 2 usually hold for real production systems: Firstly, $a_{i}$ usually is a big number, while $n_{i}$ usually is negative (or a very small positive value) to ensure that the understocking risk of return is low $\Theta_{i}\left(n_{i} \sigma_{i}^{r}\right)$ is also a small value, therefore it is easy to satisfy the condition that $a_{i}-n_{i} \sigma_{i}^{r}-\Theta_{i}\left(n_{i} \sigma_{i}^{r}\right)>0$. Secondly, the remanufacturing cost, $c r_{i}$, is usually about $50 \%$ (or less) of the manufacturing cost $c p_{i}$, and the capacity used for remanufacturing also is much less than that for producing brand-new product, that is, $r s_{i}<m s_{i}$ (Dowlatshahi 2000). Thus, the second condition can be satisfied by most practical systems.

Proposition 2 shows that the manufacturer would not produce any brand-new product $i$ if the remanufactured products can satisfy the demand since the remanufacturing cost is lower. The remanufacturing quantity given in Proposition 2 gives the upper bound of the remanufacturing quantity. By the relationship between recycling price and the remanufacturing quantity in Proposition 1, it follows that there is also an upper bound for the recycling price.

By Proposition 2, Subproblem $L R P_{i}$ can be reformulated as three single-variable subproblems. 
Subproblem $L R P_{i-1}$ :

Max

$$
\begin{aligned}
L R P_{i-1} & =\int_{0}^{Q_{i}}\left[p_{i} D_{i}-s_{i}\left(Q_{i}-D_{i}\right)\right] f_{i}^{d}\left(D_{i}\right) d D_{i}+\int_{Q_{i}}^{\infty}\left[p_{i} Q_{i}-g_{i}\left(D_{i}-Q_{i}\right)\right] f_{i}^{d}\left(D_{i}\right) d D_{i} \\
& -\left(c p_{i}+\lambda m s_{i}\right)\left(Q_{i}-X r_{i}^{H}\right)-\left[c r_{i}+\eta r s_{i}+\frac{1}{b_{i}} \ln \left(\frac{X r_{i}^{H}-n_{i} \sigma_{i}^{r}}{a_{i}}\right)\right] X r_{i}^{H} \\
& -\int_{n_{i} \sigma_{i}^{r}}^{B_{i}}\left[h r_{i}+\frac{1}{b_{i}} \ln \left(\frac{X r_{i}^{H}-n_{i} \sigma_{i}^{r}}{a_{i}}\right)\right]\left(u_{i}-n_{i} \sigma_{i}^{r}\right) f_{i}^{r}\left(u_{i}\right) d u_{i}
\end{aligned}
$$

subject to $Q_{i} \geq X r_{i}^{H}$.

Subproblem $L R P_{i-2}$ :

Max

$$
\begin{aligned}
\operatorname{LRP}_{i-2} & =\int_{0}^{Q_{i}}\left[p_{i} D_{i}-s_{i}\left(Q_{i}-D_{i}\right)\right] f_{i}^{d}\left(D_{i}\right) d D_{i}+\int_{Q_{i}}^{\infty}\left[p_{i} Q_{i}-g_{i}\left(D_{i}-Q_{i}\right)\right] f_{i}^{d}\left(D_{i}\right) d D_{i} \\
& \quad\left[c r_{i}+\eta r s_{i}+\frac{1}{b_{i}} \ln \left(\frac{Q_{i}-n_{i} \sigma_{i}^{r}}{a_{i}}\right)\right] Q_{i}-\int_{n_{i} \sigma_{i}^{r}}^{B_{i}}\left[h r_{i}+\frac{1}{b_{i}} \ln \left(\frac{Q_{i}-n_{i} \sigma_{i}^{r}}{a_{i}}\right)\right]\left(u_{i}-n_{i} \sigma_{i}^{r}\right) f_{i}^{r}\left(u_{i}\right) d u_{i}
\end{aligned}
$$

subject to $a_{i}+n_{i} \sigma_{i}^{r} \leq Q_{i} \leq X r_{i}^{H}$.

Subproblem $L R P_{i-3}$ :

Max

$$
\begin{aligned}
L R P_{i-3} & =\int_{0}^{Q_{i}}\left[p_{i} D_{i}-s_{i}\left(Q_{i}-D_{i}\right)\right] f_{i}^{d}\left(D_{i}\right) d D_{i}+\int_{Q_{i}}^{\infty}\left[p_{i} Q_{i}-g_{i}\left(D_{i}-Q_{i}\right)\right] f_{i}^{d}\left(D_{i}\right) d D_{i} \\
& -\left(c r_{i}+\eta r s_{i}\right) Q_{i}-\int_{Q_{i}-a_{i}}^{B_{i}} h r_{i}\left(u_{i}-Q_{i}+a_{i}\right) f_{i}^{r}\left(u_{i}\right) d u_{i}
\end{aligned}
$$

subject to $0 \leq Q_{i} \leq a_{i}+n_{i} \sigma_{i}^{r}$.

Subproblem $L R P_{i}$ can be solved by solving the three single-variable subproblems $L R P_{i-1}, L R P_{i-2}$ and $L R P_{i-3} . L R P_{i-1}$ is a single-product single-period newsvendor problem which can be solved easily.

Proposition 3: Function $L R P_{i-2}$ is concave in the region $\left[a_{i}+n_{i} \sigma_{i}^{r}, X r_{i}^{H}\right]$.

Proposition 4: Function $L R P_{i-3}$ is concave.

The proofs of Propositions 3 and 4 are provided in the Appendix.

\subsubsection{Solution algorithm of subproblem $L R P_{i}$}

By Propositions 1-4, the following algorithm can be developed to solve subproblem $L R P_{i}$. Let $Q_{i}^{j *}$ denote the optimal solution for $L R P_{i-j}$, for $j=1,2,3$.

\section{Algorithm A:}

Step 0: Initialization

Initialize subproblem $L R P_{i}$ and calculate $X r_{i}^{H}$ by solving equation $d L R P 2_{i} / d X r_{i}=0$.

Step 1: Solve subproblem $L R P_{i-1}$

Solve equation $d L R P_{i-1} / d Q_{i}=0$ and obtain its optimal solution $Q_{i}^{1}$.

If $Q_{i}^{1}>X r_{i}^{H}, Q_{i}^{1 *}=Q_{i}^{1}$; otherwise $Q_{i}^{1 *}=X r_{i}^{H}$

Step 2: Solve subproblem $L R P_{i-2}$

Let $D 2=d L R P_{i-2} / d Q_{i}$.

If $D 2\left(a_{i}+n_{i} \sigma_{i}^{r}\right) * D 2\left(X r_{i}^{H}\right)>0, \quad Q_{i}^{2 *}=\operatorname{argmax}\left\{D 2\left(a_{i}+n_{i} \sigma_{i}^{r}\right) D 2\left(X r_{i}^{H}\right)\right\}$;

otherwise solve equation $d L R P_{i-2} / d Q_{i}=0$ and obtain its optimal solution $Q_{i}^{2 *}$.

Step 3: Solve subproblem $L R P_{i-3}$

Let $D 3=d L R P_{i-3} / d Q_{i}$.

If $D 3(0) * D 3\left(a_{i}+n_{i} \sigma_{i}^{r}\right)>0, Q_{i}^{3 *}=\operatorname{argmax}\left\{D 3(0), D 3\left(a_{i}+n_{i} \sigma_{i}^{r}\right)\right\}$; 
otherwise solve equation $d L R P_{i-3} / d Q_{i}=0$ and obtain its optimal solution $Q_{i}^{3 *}$.

\section{Step 4: Evaluate}

The optimal stocking quantity for subproblem $L R P_{i}$ is

$Q_{i}^{*}=\operatorname{argmax}\left\{L R P_{i-1}\left(Q_{i}^{1 *}\right) L R P_{i-2}\left(Q_{i}^{2 *}\right) L R P_{i-3}\left(Q_{i}^{3 *}\right)\right\}$.

The optimal values for the other variables are obtained by Proposition 2.

Since the investigation of this paper focuses on the hybrid system, that is, the demand for the product is big and the manufacturer need to produce both brand-new and remanufactured products. Thus usually the optimal solutions for subproblems $L R P_{i-2}$ and $L R P_{i-3}$ are obtained at $X r_{i}^{H}$ and $a_{i}+n_{i} \sigma_{i}^{r}$ respectively. Only in the special case that the demand for the product is very small and the hybrid system is changed into purely remanufacturing system, should $d L R P_{i-2} / d Q_{i}=0$ and $d L R P_{i-3} / d Q_{i}=0$ need to be solved. In this situation, the function provided by Matlab is employed to solve them.

\subsection{Solving the Lagrangian Dual Problem}

Subgradient algorithm has been widely used to solve the Lagrangian dual problem, but the detail of procedure may be quiet different for different problems. In this Section, the subgradient algorithm is presented to solve the Lagrangian dual problem and obtain an upper bound on the optimal objective value of model (1)-(7). The detailed procedure is described as follows:

Step 0: Initialization

Set $\lambda=\lambda_{0}, \eta=\eta_{0}$ and $\alpha=2$,

let $L B$ be a lower bound for the problem, and initialize $L B=0$,

let $L R$ be the objective value of the relaxed problem, and initialize $L R=0$,

let $U B$ be the best upper bound for the original problem, and initialize $U B=+\infty$.

$\lambda_{0}$ and $\eta_{0}$ are estimated values for the multipliers $\lambda$ and $\eta$ respectively.

Step 1: Solve the relaxed problem

Given $\lambda$ and $\eta$, solve all the subproblems $L R P_{i}$, for $i=1, \ldots, I$, by Algorithm A, and obtain the objective value of $L R$.

Step 2: Update upper bound

If $U B>L R$, update $U B=L R$.

If there is no improvement on $U B$ after $N$ iterations, set $\alpha=\alpha / 2$,

where $N$ is a parameter set according to the problem and here $N=10$.

Step 3: Update lower bound

If $L R>L B$ and the solution satisfies constraints (2) and (3), set $L B=L R$.

Step 4: Calculate new step size

Let $n o r m=\left(M C-\sum_{i=1}^{I} m s_{i} X p_{i}\right)^{2}+\left(R C-\sum_{i=1}^{I} r s_{i} X r_{i}\right)^{2}$,

if norm $>0$, stepsize $=\alpha(L R-L B) /$ norm;

otherwise stepsize $=$ stepsize $/ 2$. 
Step 5: Update multiplier

$$
\begin{aligned}
& \lambda=\max \left\{0, \lambda-\text { stepsize } *\left(M C-\sum_{i=1}^{I} m s_{i} X p_{i}\right)\right\}, \\
& \text { and } \eta=\max \left\{0, \eta-\text { stepsize } *\left(R C-\sum_{i=1}^{I} r s_{i} X r_{i}\right)\right\} . \\
& \text { If } \lambda>\lambda_{\max }, \lambda=\lambda_{\max } / 2 . \\
& \text { If }-\frac{a_{i}+n_{i} \sigma_{i}^{r}+\Theta\left(n_{i} \sigma_{i}^{r}\right)}{a_{i} b_{i}}+\left(c p_{i}+\lambda m s_{i}\right)-\left(c r_{i}+\eta r s_{i}\right)<0, \text { set } \eta=\lambda-1 .
\end{aligned}
$$

Here $\lambda_{\max }$ is the upper bound of $\lambda$, which is explained later.

Step 6: Stopping criteria

If iteration times $>N i$ or the gaps of $\lambda$ and $\eta$ between two coterminous iterations are both less than 3, STOP; otherwise GOTO Step 1.

Here $\mathrm{Ni}$ and 3 are parameters defined according to requirement.

In the subgradient algorithm, a good solution can be obtained in less number of iterations by properly updating the multipliers. As the step size determines how far the multipliers will go along the subgradients, thus its calculating strategy has an important influence on the efficiency of the algorithm (Wolsey, 1999; D'alfanso et al., 1995).

Not only updating of the multipliers is important, but also there are some restrictions on the Lagrange multipliers that should be noticed.

\section{There is an upper bound for the Lagrangian multiplier $\lambda$}

From the property of the single-period newsvendor problem, it can be known that the optimal value of $Q_{i}$ that maximizes the objective function $L R P_{i-1}$ is

$$
Q_{i}^{1 *}=F_{i}^{d^{-1}}\left(\frac{p_{i}+g_{i}-c p_{i}-\lambda m s_{i}}{p_{i}+g_{i}+s_{i}}\right) .
$$

In order to make the above function meaningful, the Lagrange multiplier $\lambda$ must satisfy

$$
\lambda \leq \frac{p_{i}+g_{i}-c p_{i}}{m s_{i}}, \text { for } i=1, \ldots I .
$$

Let $\lambda_{\max }=\min \left\{\frac{p_{i}+g_{i}-c p_{i}}{m s_{i}} \mid \forall i\right\}$, then $\lambda_{\max }$ is the upper bound of $\lambda$.

From Proposition 2, one of the sufficient conditions is related with the multipliers, that is,

$$
-\frac{a_{i}+n_{i} \sigma_{i}^{r}+\Theta\left(n_{i} \sigma_{i}^{r}\right)}{a_{i} b_{i}}+\left(c p_{i}+\lambda m s_{i}\right)-\left(c r_{i}+\eta r s_{i}\right)>0 .
$$

When updating the multipliers, some unreasonable values of the multipliers may be produced. If conditions (a) and (b) are violated, the values of the multipliers can not be optimal to the problem. Thus in each iteration, the multipliers must be checked and adjusted if conditions (a) and (b) are violated. The computational results in Section 5 show that the above updating strategy for the Lagrange multipliers can help to obtain a good solution in less iterations. 


\subsection{Feasibility algorithm}

Although the solution obtained from the subgradient algorithm provides a good upper bound for the optimal objective value of the original problem, it can not be always primal feasible to model (1)-(7), because it may violate constraints (2) or (3). Thus, a feasibility algorithm is developed to form a feasible solution from the dual solution.

The feasibility algorithm is described as follows.

Step 1: Check constraint (2).

If constraint (2) is violated, sort the products in the ascending order in terms of unit manufacturing capacity consuming.

Decrease the manufacturing quantities for the products in the order until the total manufacturing capacity reaches its balance.

Step 2: Check constraint (3).

If constraint (3) is violated, sort the products in the ascending order in terms of unit remanufacturing capacity consuming.

Decrease the remanufacturing quantities for the products in the order until the total remanufacturing capacity reaches its balance.

Step 3: Recalculate the recycling prices.

Recalculate the optimal recycling prices for the used products according to their adjusted remanufacturing quantities by Proposition 1 .

The basic idea of the feasibility algorithm is straightforward. Computational experience shows that, for most of the problems, the feasible solution usually can be obtained by adjusting only one product's stocking quantity because the Lagrangian dual solutions are very near to the optimal solution.

The framework of the solution approach is presented in Figure 2.

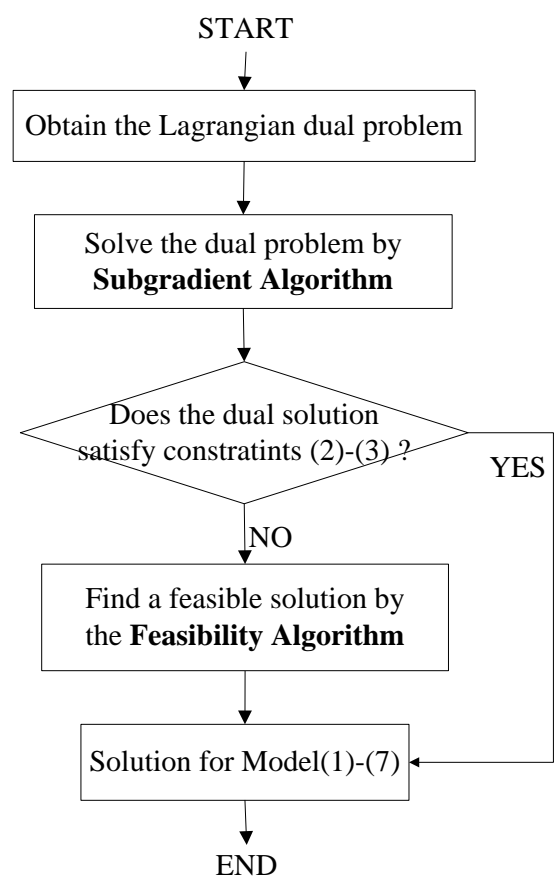

Figure 2. The framework for the Lagrangian relaxation based approach 


\section{Computational results and managerial analysis}

All of the algorithms are implemented by MARLAB. The computational experiences for the examples are conducted on the IBM T60 laptop with Windows XP (Intel® Core ${ }^{\mathrm{TM}} 2$ Duo CPU, 1GB of RAM).

\subsection{Numerical example}

In this section, a numerical example reflecting real business situation is presented to illustrate the hybrid production system. In the system, the manufacturer manages one manufacturing plant and one remanufacturing facility which produces the brand-new product and remanufactures the used products respectively. Five different types of products are produced and all of their demands follow normal distribution. The uncertain parts for the return, $z_{i}$, for $i=1, \ldots, 5$, also follow normal distribution with mean of zero. The capacity for the manufacturing plant is 20000 and the capacity for the remanufacturing facility is 11000 . Moreover, $n_{i}$ is set to -0.25 for $i=1, \ldots, 5$. The other parameters of the example are presented in Table 1.

Table 1. Parameters for the example

\begin{tabular}{c|ccccccccccccc}
\hline product & $p_{i}$ & $c p_{i}$ & $g_{i}$ & $s_{i}$ & $\mu_{i}^{d}$ & $\sigma_{i}^{d}$ & $a_{i}$ & $b_{i}$ & $\sigma_{i}^{r}$ & $c r_{i}$ & $h r_{i}$ & $m s_{i}$ & $r s_{i}$ \\
\hline 1 & 195 & 97.65 & 78.1 & 39.05 & 2000 & 880 & 335 & 0.036 & 340 & 35.05 & 13.65 & 3.72 & 3.2 \\
2 & 170 & 85.2 & 68.15 & 34.08 & 2450 & 670 & 380 & 0.041 & 280 & 36.28 & 11.93 & 3.34 & 2.08 \\
3 & 190 & 97.69 & 78.16 & 39.07 & 2260 & 675 & 260 & 0.045 & 270 & 41.72 & 13.67 & 2.95 & 2.29 \\
4 & 160 & 79.9 & 63.93 & 31.96 & 1800 & 745 & 430 & 0.038 & 285 & 30.16 & 11.18 & 3.85 & 3.62 \\
5 & 185 & 92.05 & 73.64 & 36.81 & 2320 & 695 & 325 & 0.042 & 360 & 42.35 & 12.89 & 3.21 & 2.24 \\
\hline
\end{tabular}

The example is first solved by the Lagrangian based approach and the solution is presented in Table 2. The optimal profit obtained by the Lagrangian based approach is 621,470.12. Furthermore, the example is solved by the General Algebraic Modeling System (GAMS), and the solution is presented in Table 3. GAMS is a high-level modeling system for mathematical programming and optimization. The optimal profit obtained by GAMS is 621,531.36. Comparing the two solutions, it can be seen that the Lagrangian based approach presents a solution that is very close to the optimum. The computational time for the Lagrangian based approach is 0.735 second, while GAMS presents the solution by 1.084 second.

Table 2. Solution for the example obtained by the Lagrangian based approach

\begin{tabular}{c|ccccc}
\hline product & $Q_{i}$ & $X p_{i}$ & $X r_{i}$ & $\operatorname{Pr}_{i}$ & $z_{i}$ \\
\hline 1 & 1854 & 1097 & 757 & 25.61 & -85.00 \\
2 & 2332 & 1156 & 1176 & 28.96 & -70.00 \\
3 & 2178 & 1201 & 977 & 30.90 & -67.50 \\
4 & 1614 & 1073 & 541 & 9.28 & -71.25 \\
5 & 2228 & 1365 & 863 & 25.62 & -90.00 \\
\hline \multicolumn{5}{|c|}{ Table 3. Solution for the example obtained by GAMS } & \\
\hline product & $Q_{i}$ & $X p_{i}$ & $X r_{i}$ & $\operatorname{Pr}_{i}$ & $z_{i}$ \\
\hline 1 & 1856 & 1099 & 757 & 25.61 & -85.00 \\
2 & 2331 & 1154 & 1177 & 28.99 & -70.00 \\
3 & 2178 & 1201 & 977 & 30.91 & -67.50 \\
4 & 1615 & 1075 & 540 & 9.26 & -71.25 \\
5 & 2227 & 1363 & 864 & 25.64 & -90.00 \\
\hline
\end{tabular}




\subsection{Managerial analysis}

By the above example, sensitivity analyses are conducted for several key parameters to gain some insight into the hybrid manufacturing and remanufacturing system.

\section{The manufacturer's profit versus manufacturing and remanufacturing capacities}

Sensitivity analyses are conducted for the manufacturing capacity and the remanufacturing capacity, and the results are shown as graphs in Figures 3 and 4. From Figure 3, it can be seen that the total expected profit of the manufacturer increases when the manufacturing capacity increases, but it stays unchanged beyond about $M C=24,000$. Similarly, Figure 4 illustrates that the manufacturer's total profit increases as the remanufacturing capacity increases, and it will remain unchanged when the remanufacturing capacity is over 15,000 . The analysis shows that the manufacturer can increase his profit by increasing the capacities of the facilities, but there are specific limits for each of the facility. Beyond these limits, additional profit will not be obtained anymore, because the additional capacities are not fully utilized due to the limitation of demands.

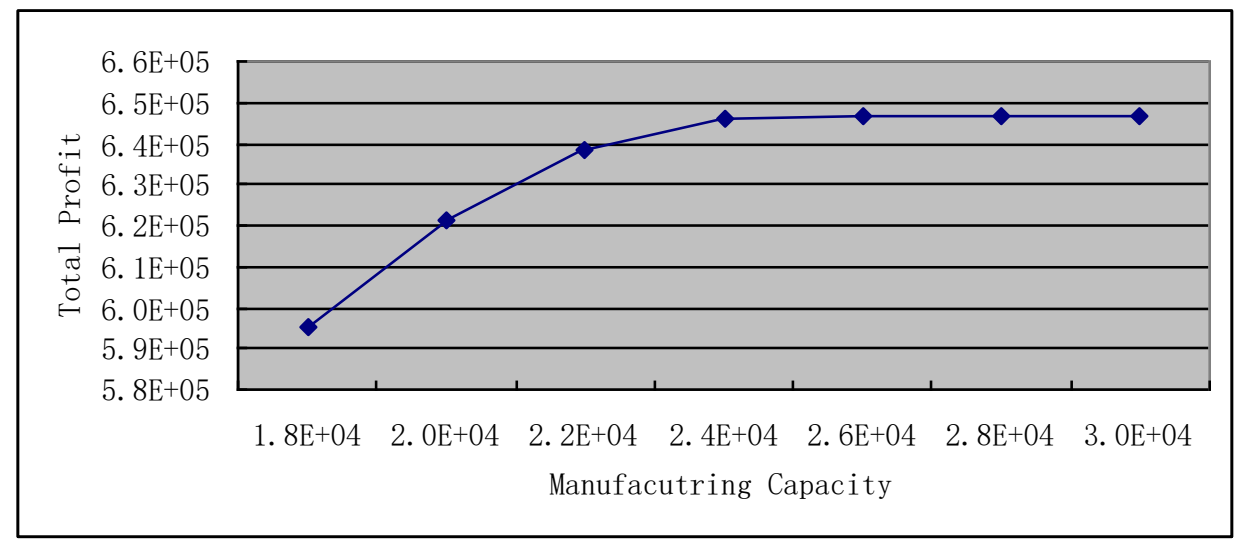

Figure 3. The optimal expected profit under different manufacturing capacities

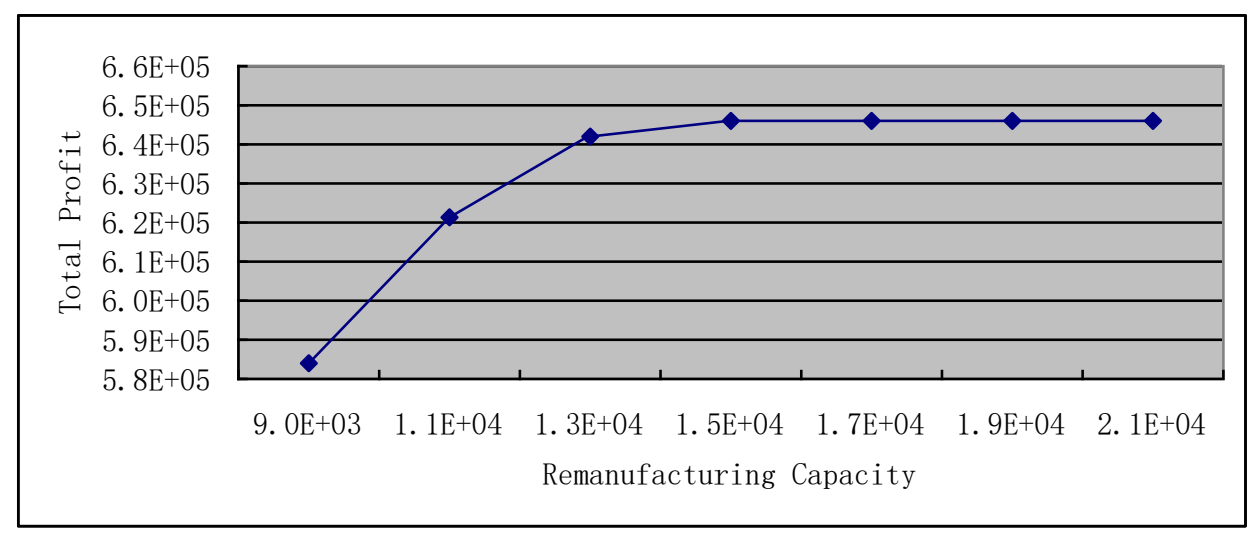

Figure 4. The optimal expected profit under different remanufacturing capacities

\section{The stocking quantity versus the standard deviation of a product's demand}

The relationship between the stocking quantity and the standard deviation of a product's demand also is investigated. Figure 5 shows that the stocking quantity of product 1 decreases when the standard deviation of its demand increases. It indicates that the manufacturer shifts the capacity from product 1 to other products with relatively lower risk to reduce profit loss. It can also be seen that the manufacturing quantity decreases very quickly while there is no much vary on the remanufacturing quantity. The analysis shows that the change of the 
standard deviation of a product's demand has more influence on the manufacturing plan than the remanufacturing plan.

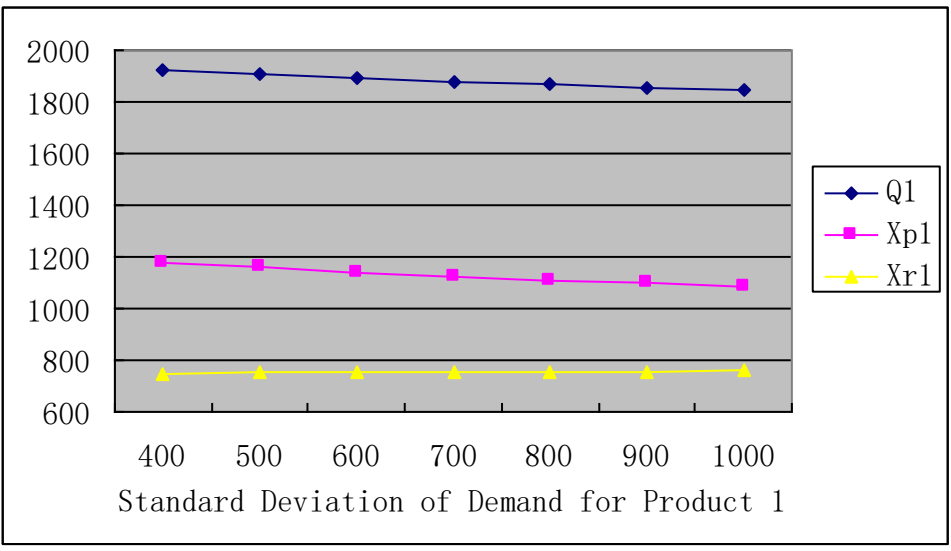

Figure 5. The manufacturing and remanufacturing quantities under different value of $\sigma_{1}^{d}$

\section{The production and recycling policy versus the standard deviation of a product's return}

Figures 6 and 7 investigate how the production and recycling policy changes as the standard deviation of the return for product 1 varies from 150 to 450. Figure 6 illustrates that the manufacturing quantity of product 1 increases when the standard deviation of its return increases, while its remanufacturing quantity decreases, but the total stocking quantity does not show much change. It indicates that, when the uncertainty on return increases, the manufacturer more likely satisfies the demands by producing the brand-new products than by remanufacturing used products. Figure 7 shows that the recycling price of used product 1 decreases when the standard deviation of its return increases. It indicates that the manufacturer tends to pay less for the used products with higher uncertainty. Figures 6 and 7 show that the uncertainty of the return does have much influence on its production and recycling policy.

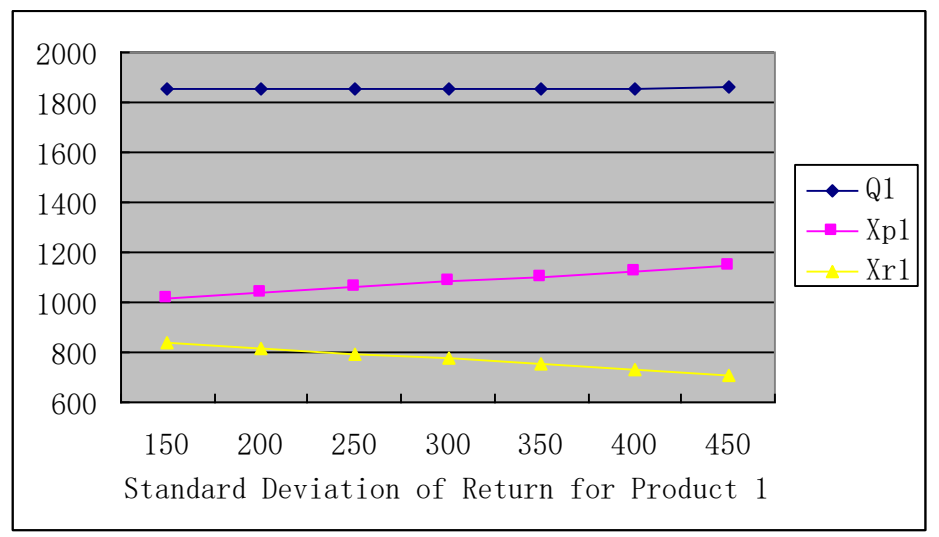

Figure 6. The manufacturing and manufacturing quantities under different value of $\sigma_{1}^{r}$ 


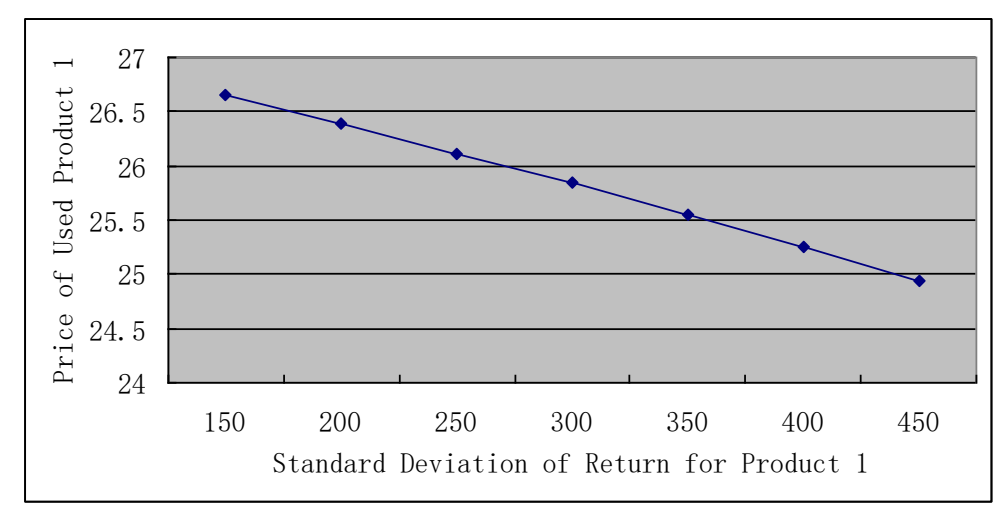

Figure 7. The acquisition price of used product 1 under different value of $\sigma_{1}^{r}$

\subsection{Performance of the solution approaches}

In order to further affirm the robustness of the solution approach, twenty numerical examples are randomly produced and solved: ten of them are small size examples that involve 5 products, and the other ten examples are large size that involves 50 products. The data for all the twenty examples can be obtained from the authors on request.

Table 4 illustrates the computational results for all the examples. The upper bound means the optimal objective value for the relaxed problem obtained by the subgradient algorithm. The relative gap is defined as (upper bound-feasible solution)/ feasible solution. In Table 4, the maximal relative gap for the small size examples is 3.50E-05, while the maximal relative gap for the large size examples is $1.49 \mathrm{E}-05$. It can be seen that the Lagrangian based solution approach can present very good solution to all the examples. The computational time for the small examples is controlled in 1 second, while the large examples' is a little longer, but still controlled in 10 seconds. In all, the Lagrangian based approach can present very good solution for all examples in acceptable computational time.

Table 4. Computational results of the solution approaches.

\begin{tabular}{|c|c|c|c|c|c|c|c|c|c|c|}
\hline $\begin{array}{c}\text { Problem } \\
\text { size }\end{array}$ & \multicolumn{5}{|c|}{5 products } & \multicolumn{6}{c|}{50 products } \\
\hline & $\begin{array}{c}\text { Upper } \\
\text { Bound }\end{array}$ & $\begin{array}{c}\text { Feasible } \\
\text { Solution }\end{array}$ & $\begin{array}{c}\text { Absolute } \\
\text { Gap }\end{array}$ & $\begin{array}{c}\text { Relative } \\
\text { Gap }\end{array}$ & $\begin{array}{c}\text { Time } \\
\text { Used(s) }\end{array}$ & $\begin{array}{c}\text { Upper } \\
\text { Bound }\end{array}$ & $\begin{array}{c}\text { Feasible } \\
\text { Solution }\end{array}$ & $\begin{array}{c}\text { Absolute } \\
\text { Gap }\end{array}$ & $\begin{array}{c}\text { Relative } \\
\text { Gap }\end{array}$ & $\begin{array}{c}\text { Time } \\
\text { Used(s) }\end{array}$ \\
\hline 1 & 755557.86 & 755555.44 & 2.41 & $3.19 \mathrm{E}-06$ & 0.682 & 6564930.91 & 6564892.27 & 38.64 & $5.89 \mathrm{E}-06$ & 8.215 \\
\hline 2 & 706432.20 & 706432.14 & 0.05 & $7.34 \mathrm{E}-08$ & 0.617 & 6890517.62 & 6890509.13 & 8.49 & $1.23 \mathrm{E}-06$ & 9.306 \\
\hline 3 & 661391.06 & 661391.04 & 0.02 & $2.74 \mathrm{E}-08$ & 0.793 & 6595094.58 & 6595070.82 & 23.76 & $3.60 \mathrm{E}-06$ & 6.958 \\
\hline 4 & 785846.50 & 785776.40 & 70.10 & $8.92 \mathrm{E}-05$ & 0.926 & 7282701.88 & 7282687.13 & 14.75 & $2.03 \mathrm{E}-06$ & 7.549 \\
\hline 5 & 762307.00 & 762306.29 & 0.71 & $9.33 \mathrm{E}-07$ & 0.674 & 7120688.41 & 7120679.73 & 8.68 & $1.22 \mathrm{E}-06$ & 7.863 \\
\hline 6 & 636659.94 & 636652.94 & 7.00 & $1.10 \mathrm{E}-05$ & 0.805 & 6826744.79 & 6826726.18 & 18.61 & $2.73 \mathrm{E}-06$ & 8.914 \\
\hline 7 & 697502.70 & 697500.14 & 2.56 & $3.67 \mathrm{E}-06$ & 0.824 & 6998789.43 & 6998745.63 & 43.80 & $6.26 \mathrm{E}-06$ & 9.025 \\
\hline 8 & 628405.01 & 628404.94 & 0.07 & $1.04 \mathrm{E}-07$ & 0.751 & 6996886.22 & 6996841.97 & 44.25 & $6.32 \mathrm{E}-06$ & 8.782 \\
\hline 9 & 679360.32 & 679336.53 & 23.80 & $3.50 \mathrm{E}-05$ & 0.749 & 6972501.39 & 6972495.66 & 5.73 & $8.22 \mathrm{E}-07$ & 7.497 \\
\hline 10 & 660059.20 & 660049.43 & 9.77 & $1.48 \mathrm{E}-05$ & 0.837 & 6909374.55 & 6909271.93 & 102.62 & $1.49 \mathrm{E}-05$ & 7.395 \\
\hline
\end{tabular}

Table 5 shows the solutions when the $M C$ capacity varies from 16000 to 22000 for the example in Section 5.1. Columns LS and FA are the objective values from Lagrangian heuristic without and with feasibility algorithm respectively. Columns Gap1 and Gap2 evaluate the gap of LS and FA to upper bound. 
The last column represents relative gap of solutions with feasibility algorithm. Comparing Gap2 with Gap1, it is noted that the average gap is reduced from 6853.76 to 79.14 by employing feasible algorithm. It implies the feasible algorithm obviously improves the solution. From Table 5 we find that although there are some fluctuations on the gaps, the relative gaps vary from $8.68 \mathrm{E}-06$ to $4.27 \mathrm{E}-04$ with the average of $1.33 \mathrm{E}-04$. It illustrates that the proposed approach performs well as the capacity varies in the range.

Table 5. Computational results under different $M C$ capacities.

\begin{tabular}{|c|c|c|c|c|c|c|}
\hline$M C$ & $\begin{array}{c}\text { Lagrangian } \\
\text { Solution (LS) }\end{array}$ & $\begin{array}{c}\text { With Feasibility } \\
\text { Algorithm (FA) }\end{array}$ & $\begin{array}{c}\text { Upper } \\
\text { Bound (UB) }\end{array}$ & $\begin{array}{c}\text { Gap1 } \\
\text { (UB-LS) }\end{array}$ & $\begin{array}{c}\text { Gap2 } \\
\text { (UB-FA) }\end{array}$ & $\begin{array}{c}\text { Relative } \\
\text { Gap }\end{array}$ \\
\hline 16000 & 557099.93 & 560764.44 & 560781.08 & 3681.15 & 16.64 & $2.97 \mathrm{E}-05$ \\
\hline 17000 & 572272.64 & 579097.44 & 579275.07 & 7002.43 & 177.63 & $3.07 \mathrm{E}-04$ \\
\hline 18000 & 584833.04 & 595311.15 & 595565.10 & 10732.06 & 253.95 & $4.27 \mathrm{E}-04$ \\
\hline 19000 & 585336.04 & 609631.35 & 609640.54 & 24304.50 & 9.19 & $1.51 \mathrm{E}-05$ \\
\hline 20000 & 621250.71 & 621470.12 & 621533.46 & 282.75 & 63.33 & $1.02 \mathrm{E}-04$ \\
\hline 21000 & 630099.47 & 631155.03 & 631160.51 & 1061.04 & 5.48 & $8.68 \mathrm{E}-06$ \\
\hline 22000 & 637590.16 & 638474.78 & 638502.57 & 912.41 & 27.79 & $4.35 \mathrm{E}-05$ \\
\hline Average & & & & 6853.76 & 79.14 & $1.33 \mathrm{E}-04$ \\
\hline
\end{tabular}

When the capacities become large enough, the multi-product problem can be directly decomposed into single-product problems without taking into account constraints (2) and (3) since they are always satisfied with the solution of single-product problems. The exactly optimal solution of the single-product problems can be obtained without applying the Lagrangian method. When the capacities become too low, more issues, such as product list selection, hybrid system optimization, should be considered. The solution approach on the scenario is beyond the range of this research, but deserves for the future study.

\section{Conclusions}

This paper investigates the joint production and recycling problem for a hybrid manufacturing and remanufacturing system. A mathematical model is developed for the problem, in which the total expected profit is maximized through determining the production quantities of bran-new products, the recycling prices of the used products and their remanufacturing quantities. A Lagrangian based solution approach is developed to solve the problem. A numerical example is presented to illustrate the problem and gain some insight into the hybrid system. Sensitivity analyses show that the uncertainty of demand has more influence on manufacturing than remanufacturing, while the uncertainty of return has much more impact on both production and recycling policy. Furthermore, twenty randomly produced examples are used to test the solution approach. Computational results show that the solution approach can present very good solutions to all the examples.

The understocking cost of the return is not considered in the proposed model. The estimation for the cost depends how to find substituted parts for the remanufacturing when the return is less than expected. Further research on the exact formulation of the expect profit and optimization analysis for the hybrid remanufacturing system is needed. Furthermore, in practical closed loop supply chains, there are usually multiple options for the recovery of used products, such as direct reuse, repair, refurbishing, remanufacturing, and cannibalization since the used products have different quality. Therefore an important extension to our model is to incorporate multiple recovery options and more flexible recycling strategy with considering the quality of returned products, which will make the model more practical and applicable. In addition, form methodology point of view, it deserves to develop different solution methods and compare their performance, especially for large scale hybrid manufacturing and remanufacturing systems with the large number of products. 


\section{Acknowledgment}

This research is supported by NSERC Discovery grant (298482), Canada Foundation for Innovation, and China State Scholarship Fund. We would like to thank the anonymous reviewers for their comments and suggestions that helped improve this paper.

\section{Appendix}

\section{Proof of Proposition 1}

As $X r_{i}=a_{i} e^{b_{i} \operatorname{Pr}_{i}}+z_{i}$, we can obtain $\operatorname{Pr}_{i}=\frac{1}{b_{i}} \ln \left(\frac{X r_{i}-z_{i}}{a_{i}}\right)$.

Substitute $\operatorname{Pr}_{i}\left(z_{i}\right)$ to $T R C_{i}$, then

$T R C_{i}\left[z_{i}, \operatorname{Pr}_{i}\left(z_{i}\right)\right]=\left[c r_{i}+\eta r s_{i}+\frac{1}{b_{i}} \ln \left(\frac{X r_{i}-z_{i}}{a_{i}}\right)\right] X r_{i}+\int_{z_{i}}^{B_{i}}\left[h r_{i}+\frac{1}{b_{i}} \ln \left(\frac{X r_{i}-z_{i}}{a_{i}}\right)\right]\left(u_{i}-z_{i}\right) f_{i}^{r}\left(u_{i}\right) d u_{i}$.

The first derivative of function $\operatorname{TRC}_{i}\left[z_{i}, \operatorname{Pr}_{i}\left(z_{i}\right)\right]$ is

$$
\begin{aligned}
& \frac{d T R C_{i}\left[z_{i}, \operatorname{Pr}_{i}\left(z_{i}\right)\right]}{d z_{i}}=-\frac{X r_{i}}{b_{i}\left(X r_{i}-z_{i}\right)}-\left[h r_{i}+\frac{1}{b_{i}} \ln \left(\frac{X r_{i}-z_{i}}{a_{i}}\right)\right]\left[1-F_{i}^{r}\left(z_{i}\right)\right] \\
& -\frac{1}{b_{i}\left(X r_{i}-z_{i}\right)} \int_{z_{i}}^{B_{i}}\left(u_{i}-z_{i}\right) f_{i}^{r}\left(u_{i}\right) d u_{i} \\
& \text { and } \frac{d T R C_{i}\left[z_{i}, \operatorname{Pr}_{i}\left(z_{i}\right)\right]}{d z_{i}}<0 \text {. }
\end{aligned}
$$

Thus $T R C_{i}\left[z_{i}, \operatorname{Pr}_{i}\left(z_{i}\right)\right]$ is a monotonically decreasing function of $z_{i}$.

Since $\operatorname{Pr}_{i}=\frac{1}{b_{i}} \ln \left(\frac{X r_{i}-z_{i}}{a_{i}}\right) \geq 0, z_{i} \leq X r_{i}-a_{i}$.

From constraint (6), $A_{i} \leq z_{i} \leq n_{i} \sigma_{i}^{r}$, thus $z^{*}=\min \left\{X r_{i}-a_{i}, n_{i} \sigma_{i}^{r}\right\}$.

If $X r_{i} \geq a_{i}+n_{i} \sigma_{i}^{r}$, then $z_{i}^{*}=n_{i} \sigma_{i}^{r}$, and $\operatorname{Pr}_{i}^{*}=\frac{1}{b_{i}} \ln \left(\frac{X r_{i}-n_{i} \sigma_{i}^{r}}{a_{i}}\right)$ which is obtained by substituting $z_{i}^{*}=n_{i} \sigma_{i}^{r}$ into $\operatorname{Pr}_{i}\left(z_{i}\right)$.

If $X r_{i} \leq a_{i}+n_{i} \sigma_{i}$, then $z_{i}^{*}=X r_{i}-a_{i}$ and $\operatorname{Pr}_{i}^{*}=0$.

\section{Proof of Proposition 2}

First, if the nonnegative restriction of $\operatorname{Pr}_{i}$ is relaxed, form Proposition 1, it can be known that, for a fixed $X r_{i}$, the optimal values of $\operatorname{Pr}_{i}$ and $z_{i}$ are $\operatorname{Pr}_{i}^{*}=\frac{1}{b_{i}} \ln \left(\frac{X r_{i}-n_{i} \sigma_{i}^{r}}{a_{i}}\right)$ and $z_{i}^{*}=n_{i} \sigma_{i}^{r}$.

Substitute them into the objective function (8), then 


$$
\begin{aligned}
& L R P 1_{i}=\int_{0}^{Q_{i}}\left[p_{i} D_{i}-s_{i}\left(Q_{i}-D_{i}\right)\right] f_{i}^{d}\left(D_{i}\right) d D_{i}+\int_{Q_{i}}^{\infty}\left[p_{i} Q_{i}-g_{i}\left(D_{i}-Q_{i}\right)\right] f_{i}^{d}\left(D_{i}\right) d D_{i} \\
&-\left(c p_{i}+\lambda m s_{i}\right) X p_{i}-\left[c r_{i}+\eta r s_{i}+\frac{1}{b_{i}} \ln \left(\frac{X r_{i}-n_{i} \sigma_{i}^{r}}{a_{i}}\right)\right] X r_{i} \\
&-\left[h r_{i}+\frac{1}{b_{i}} \ln \left(\frac{X r_{i}-n_{i} \sigma_{i}^{r}}{a_{i}}\right)\right] \Theta_{i}\left(n_{i} \sigma_{i}^{r}\right) \\
& \text { where } \Theta_{i}\left(n_{i} \sigma_{i}^{r}\right)=\int_{n_{i} \sigma_{i}^{r}}^{B_{i}}\left(u_{i}-n_{i} \sigma_{i}^{r}\right) f_{i}^{r}\left(u_{i}\right) d u_{i} .
\end{aligned}
$$

From constraint (4), it can be obtained that $X p_{i}=Q_{i}-X r_{i}$. Substitute it into (10), then

$$
\begin{aligned}
L R P 2_{i} & =\int_{0}^{Q_{i}}\left[p_{i} D_{i}-s_{i}\left(Q_{i}-D_{i}\right)\right] f_{i}^{d}\left(D_{i}\right) d D_{i}+\int_{Q_{i}}^{\infty}\left[p_{i} Q_{i}-g_{i}\left(D_{i}-Q_{i}\right)\right] f_{i}^{d}\left(D_{i}\right) d D_{i} \\
& -\left(c p_{i}+\lambda m s_{i}\right)\left(Q_{i}-X r_{i}\right)-\left[c r_{i}+\eta r s_{i}+\frac{1}{b_{i}} \ln \left(\frac{X r_{i}-n_{i} \sigma_{i}^{r}}{a_{i}}\right)\right] X r_{i} \\
& -\left[h r_{i}+\frac{1}{b_{i}} \ln \left(\frac{X r_{i}-n_{i} \sigma_{i}^{r}}{a_{i}}\right)\right] \Theta_{i}\left(n_{i} \sigma_{i}^{r}\right) .
\end{aligned}
$$

If $Q_{i}$ is fixed, then the first and second derivatives of $L R P 2_{i}$ are

$$
\begin{aligned}
& \frac{d L R P 2_{i}}{d X r_{i}}=-\frac{X r_{i}+\Theta_{i}\left(n_{i} \sigma_{i}^{r}\right)}{b_{i}\left(X r_{i}-n_{i} \sigma_{i}^{r}\right)}-\frac{1}{b_{i}} \ln \left(\frac{X r_{i}-n_{i} \sigma_{i}^{r}}{a_{i}}\right)+\left(c p_{i}+\lambda m s_{i}\right)-\left(c r_{i}+\eta r s_{i}\right), \\
& \text { and } \frac{d^{2} L R P 2_{i}}{d X r_{i}^{2}}=-\frac{X r_{i}-2 n_{i} \sigma_{i}^{r}-\Theta_{i}\left(n_{i} \sigma_{i}^{r}\right)}{b_{i}\left(X r_{i}-n_{i} \sigma_{i}^{r}\right)^{2}}
\end{aligned}
$$

If $a_{i}-n_{i} \sigma_{i}^{r}-\Theta_{i}\left(n_{i} \sigma_{i}^{r}\right)>0$, for any $X r_{i}$ that satisfies $X r_{i} \geq a_{i}+n_{i} \sigma_{i}^{r}, d^{2} L R P 2_{i} / d X r_{i}^{2}<0$.

$$
\begin{aligned}
& \text { If }-\frac{a_{i}+n_{i} \sigma_{i}^{r}+\Theta_{i}\left(n_{i} \sigma_{i}^{r}\right)}{a_{i} b_{i}}+\left(c p_{i}+\lambda m s_{i}\right)-\left(c r_{i}+\eta r s_{i}\right)>0, \\
& \left.\frac{d L R P 2_{i}}{d X r_{i}}\right|_{X r_{i}=a_{i}+n_{i} \delta_{i}^{r}}=-\frac{a_{i}+n_{i} \sigma_{i}^{r}+\Theta_{i}\left(n_{i} \sigma_{i}^{r}\right)}{a_{i} b_{i}}+\left(c p_{i}+\lambda m s_{i}\right)-\left(c r_{i}+\eta r s_{i}\right)>0 .
\end{aligned}
$$

Furthermore $\left.\frac{d L R P 2_{i}}{d X r_{i}}\right|_{X r_{i}=+\infty}<0$,

thus there is an unique $X r_{i}$ in the region $\left[a_{i}+n_{i} \sigma_{i}^{r},+\infty\right)$ that satisfies $d L R P 2_{i} / d X r_{i}=0$.

Let $X r_{i}^{H}$ denote the unique solution for $d L R P 2_{i} / d X r_{i}=0$.

For any fixed $Q_{i}$, if $Q_{i} \geq X r_{i}^{H}$, the optimal solutions to maximize function (10) are $X r_{i}^{*}=X r_{i}^{H}$ and $X p_{i}^{*}=Q_{i}-X r_{i}^{H}$;

if $Q_{i}<X r_{i}^{H}$, from constraints (4) and (7), we know that $X r_{i}=Q_{i}-X p_{i} \leq Q_{i}$, therefore the optimal solutions to maximize function (10) are $X r_{i}^{*}=Q_{i}$ and $X p_{i}^{*}=0$.

For any fixed $Q_{i}$ that $Q_{i} \geq a_{i}+n_{i} \sigma_{i}^{r}, X r_{i}^{*}=\min \left\{Q_{i}, X r_{i}^{H}\right\} \geq a_{i}+n_{i} \sigma_{i}^{r}$, all the above solutions satisfy constraints (4)-(7), and they are optimal for subproblem $L R P_{i}$.

Thus for any fixed $Q_{i}$ that $Q_{i} \geq X r_{i}^{H}, \operatorname{Pr}_{i}^{*}=\frac{X r_{i}-a_{i}-n_{i} \sigma_{i}^{r}}{b_{i}}, z_{i}^{*}=n_{i} \sigma_{i}^{r}, X r_{i}^{*}=X r_{i}^{H} \quad$ and $X p_{i}^{*}=Q_{i}-X r_{i}^{H}$ 
for any fixed $Q_{i}$ that $a_{i}+n_{i} \sigma_{i}^{r} \leq Q_{i}<X r_{i}^{H}, \operatorname{Pr}_{i}^{*}=\frac{X r_{i}-a_{i}-n_{i} \sigma_{i}^{r}}{b_{i}}, z_{i}^{*}=n_{i} \sigma_{i}^{r}, X r_{i}^{*}=Q_{i}$ and $X p_{i}^{*}=0$.

When $Q_{i}<a_{i}+n_{i} \sigma_{i}^{r}, X r_{i}=Q_{i}-X p_{i}<a_{i}+n_{i} \sigma_{i}^{r}$, then the nonnegativity of $\operatorname{Pr}_{i}$ must be considered. In this condition, by Proposition 1 we know that, for any fixed $X r_{i}$, the optimal values of $\operatorname{Pr}_{i}$ and $z_{i}$ are $\operatorname{Pr}_{i}^{*}=0$ and $z_{i}^{*}=X r_{i}-a_{i}$.

Substitute them and $X p_{i}=Q_{i}-X r_{i}$ into the objective function (8), we can obtain

$$
\begin{aligned}
L R P 3_{i} & =\int_{0}^{Q_{i}}\left[p_{i} D_{i}-s_{i}\left(Q_{i}-D_{i}\right)\right] f_{i}^{d}\left(D_{i}\right) d D_{i}+\int_{Q_{i}}^{\infty}\left[p_{i} Q_{i}-g_{i}\left(D_{i}-Q_{i}\right)\right] f_{i}^{d}\left(D_{i}\right) d D_{i} . \\
& -\left(c p_{i}+\lambda m s_{i}\right)\left(Q_{i}-X r_{i}\right)-\left(c r_{i}+\eta r s_{i}\right) X r_{i}-h r_{i} \Theta_{i}\left(X r_{i}-a_{i}\right)
\end{aligned}
$$

Since $\frac{d L R P 3_{i}}{d X r_{i}}=\left(c p_{i}+\lambda m s_{i}\right)-\left(c r_{i}+\eta r s_{i}\right)+h r_{i}\left[1-F_{i}^{r}\left(X r_{i}-a_{i}\right)\right]>0$ and $X r_{i}=Q_{i}-X p_{i} \leq Q_{i}$,

We can obtain the optimal solutions to maximize function (12), which are $X r_{i}^{*}=Q_{i}$ and $X p_{i}^{*}=0$.

Therefore for any fixed $Q_{i}$ that $Q_{i}<a_{i}+n_{i} \sigma_{i}^{r}, \operatorname{Pr}_{i}^{*}=0, z_{i}^{*}=X r_{i}-a_{i}, X r_{i}^{*}=Q_{i}$ and $X p_{i}^{*}=0$.

\section{Proof of Proposition 3.}

The first and second derivatives of function $L R P_{i-2}$ are as follows:

$$
\begin{aligned}
& \frac{d L R P_{i-2}}{d Q_{i}}=p_{i}+g_{i}-\left(c r_{i}+\eta r s_{i}\right)-\left(p_{i}+g_{i}+s_{i}\right) F_{i}^{d}\left(Q_{i}\right) \\
& \qquad-\frac{Q_{i}+\Theta_{i}\left(n_{i} \sigma_{i}^{r}\right)}{b_{i}\left(Q_{i}-n_{i} \sigma_{i}^{r}\right)}-\frac{1}{b_{i}} \ln \left(\frac{Q_{i}-n_{i} \sigma_{i}^{r}}{a_{i}}\right), \\
& \text { and } \frac{d^{2} L R P_{i-2}}{d Q_{i}^{2}}=-\left(p_{i}+g_{i}+s_{i}\right) f_{i}^{d}\left(Q_{i}\right)-\frac{Q_{i}-2 n_{i} \sigma_{i}^{r}-\Theta_{i}\left(n_{i} \sigma_{i}^{r}\right)}{b_{i}\left(Q_{i}-n_{i} \sigma_{i}^{r}\right)^{2}} .
\end{aligned}
$$

For $a_{i}+n_{i} \sigma_{i}^{r} \leq Q_{i}<X r_{i}^{H}, d^{2} L R P_{i-2} / d Q_{i}^{2}<0$,

thus function $L R P_{i-2}$ is concave in region $\left[a_{i}+n_{i} \sigma_{i}^{r}, X r_{i}^{H}\right]$. $\square$

\section{Proof of Proposition 4.}

The first and second derivatives of function $L R P_{i-3}$ are as follows:

$\frac{d L R P_{i-3}}{d Q_{i}}=p_{i}+g_{i}-\left(c r_{i}+\lambda r s_{i}\right)-\left(p_{i}+g_{i}+s_{i}\right) F_{i}^{d}\left(Q_{i}\right)+h r_{i}\left[1-F_{i}^{r}\left(Q_{i}-a_{i}\right)\right]$,

and $\frac{d^{2} L R P_{i-3}}{d Q_{i}^{2}}=-\left(p_{i}+g_{i}+s_{i}\right) f_{i}^{d}\left(Q_{i}\right)-h r_{i} f_{i}^{r}\left(Q_{i}-a_{i}\right)<0$.

Thus function $L R P_{i-3}$ is concave.

\section{References}

[1] Aras N., Verter V., Boyaci T. (2006) Coordination and Priority Decisions in Hybrid Manufacturing /Remanufacturing Systems. Production and Operations Management, 15(4): 528-543.

[2] Bakal I.S., Akcali E. (2006) Effects of Random Yield in Remanufacturing with Price-Sensitive Supply and Demand. Production and Operations Management, 15(3): 407-420

[3] Carter CR, Ellram LM. (1998) Reverse logistics: a review of the literature and framework for future investigation. Journal of Business Logistics, 19(1):85-102.

[4] Choi, D. W., Hwang, H., Koh, S. G. (2007) A generalized ordering and recovery policy for reusable items. European Journal of Operational Research, 182(2): 764-774. 
[5] Dobos, I., Richter, K. (2006) A production/recycling model with quality consideration. International Journal of Production Economics, 104(2): 571-579

[6] Dowlatshahi S. (2000) Developing a theory of reverse logistics. Interfaces, 30: 143-55.

[7] Fleischmann, M., Bloemhof-Ruwaard, J.M., Dekker, R. et al. (1997) Quantitative models for reverse logistics: A review. European Journal of Operational Research, 103 (1): 1-17.

[8] Fleischmann, M., Kuik, R., Dekker, R. (2002) Controlling inventories with stochastic item returns: A basic model. European Journal of Operational Research, 138(1): 63-75.

[9] Fleischmann, M., Kuik, R. (2003) On optimal inventory control with independent stochastic item returns. European Journal of Operational Research, 151(1): 25-37.

[10] Guide Jr., V.D.R. (2000) Production planning and control for remanufacturing: industry practice and research needs. Journal of Operations Management, 18(4): 467-483.

[11] Guide Jr VDR, Jayaraman V, Srivastava R, Benton WC. (2000) Supply chain management for recoverable manufacturing systems. Interfaces, 30:125-42.

[12] Guide Jr., V.D.R., Van Wassenhove, L.N. (2001) Managing product returns for remanufacturing. Production and Operations Management, 10 (2): 142-155.

[13] Guide Jr., V.D.R., Van Wassenhove, L.N. (2001) Managing product returns for remanufacturing. Production and Operations Management, 10(2): 142-155.

[14] Guide Jr., V.D.R., Teunter, R.H., Van Wassenhove, L.N. (2003) Matching Demand and Supply to Maximize Profits from Remanufacturing. Manufacturing and Service Operations Management, 5(4): 303-316.

[15] Guide Jr., V.D.R., Van Wassenhove, L.N. (2009) The evolution of closed-loop supply chain research. Operations Research, 57(1): 10-18.

[16] Inderfurth, K., Kok, A.G. and Flapper, S.D.P. (2001) Product recovery in stochastic remanufacturing systems with multiple reuse options. European Journal of Operational Research, 133: 130-152.

[17] Inderfurth, K., Van Der Laan, E. (2001) Lead time effects and policy improvement for stochastic inventory control with remanufacturing. International Journal of Production Economics, 71(1-3): pp. 381-390.

[18] Inderfurth, K. (2004) Optimal policies in hybrid manufacturing/remanufacturing systems with product substitution. International Journal of Production Economics, 90(3): 325-343.

[19] Inderfurth, K. (2005) Impact of uncertainties on recovery behavior in a remanufacturing environment: A numerical analysis. International Journal of Physical Distribution and Logistics Management, 35(5): 318-336

[20] Jayaraman V. (2006) Production planning for closed-loop supply chains with product recovery and reuse: an analytical approach. International Journal of Production Research, 44 (5): 981-998

[21] Jorjani, S., Leu, J. and Scott, C. (2004) Model for the allocation of electronics components to reuse options. International Journal of Production Research, 42(6), 1131-1145.

[22] Kim, K., Song, I., Kim, J. and Jeong, B. (2006) Supply planning model for remanufacturing system in reverse logistics system. Computers \& Industrial Engineering, 51: 279-287.

[23] Liang Y, Pokharel S, Lim GH. (2009) Pricing used products for remanufacturing. European Journal of Operational Research, 193(2): 390-395.

[24] Mitra S. (2007) Revenue management for remanufactured products, Omega: The International Journal of Management Science, 35(5): 553-562.

[25] Petruzzi N.C, Data M. (1999) Pricing and the newsvendor problem: a review with extensions, Operations Research, 47: 183-194.

[26] Pokharel, S., Mutha, A. (2009) Perspectives in reverse logistics: a review. Resources, Conservation and Recycling, 53(4): 175-182. 
[27] Qu, X., Williams, J.A.S. (2008) An analytical model for reverse automotive production planning and pricing. European Journal of Operational Research, 190(3): 756-767.

[28] Rubio, S., Corominas, A. (2008) Optimal manufacturing-remanufacturing policies in a lean production environment. Computers and Industrial Engineering, 55(1): 234-242.

[29] Rubio S, Chamorro A, Miranda F. (2008) Characteristics of the research on reverse logistics (1995-2005). International Journal of Production Research, 46(4):1099-1120.

[30] Rouf S., Zhang G. (2009) Supply planning for a closed loop system with uncertain demand and return, International Journal of Operational Research, in press.

[31] Van Der Laan, E., Salomon, M., Dekker, R., Van Wassenhove, L. (1999) Inventory control in hybrid systems with remanufacturing. Management Science, 45(5): 733-747.

[32] Zhou L., Naim M.M., Tang Q., Towill Q.R. (2006) Dynamic performance of a hybrid inventory system with a Kanban policy in remanufacturing process. Omega, 34: 585-598. 